Discussion Paper No. 981

\title{
THE COUNTERVAILING \\ POWER HYPOTHESIS \\ WHEN DOMINANT RETAILERS \\ FUNCTION AS SALES PROMOTERS
}

Noriaki Matsushima

Shohei Yoshida

October 2016

The Institute of Social and Economic Research Osaka University

6-1 Mihogaoka, Ibaraki, Osaka 567-0047, Japan 


\title{
The countervailing power hypothesis when dominant retailers function as sales promoters*
}

\author{
Noriaki Matsushima ${ }^{\dagger}$ \\ Institute of Social and Economic Research, Osaka University \\ Shohei Yoshida $a^{\ddagger}$ \\ Graduate School of Economics, Osaka University. \\ October 5, 2016
}

\begin{abstract}
We consider a downstream oligopoly model with one dominant and several fringe retailers, who purchase a manufacturing product from a monopoly supplier. We then examine how the supplier's outside option influences the relation between the dominant retailer's bargaining power and the equilibrium retail price. If the market demand shrinks due to a breakdown of bargaining between the supplier and the dominant retailer, who works as a sales promoter for the product, there is a negative relation between the bargaining power and the retail price. Furthermore, retailers' efficiency improvements increase the retail price if the dominant retailer's bargaining power is strong.
\end{abstract}

JEL codes: L13, D43.

Keywords: Countervailing power, Buyer power, Dominant retailer, Two-part tariff.

*We thank the seminar participants at Kyoto Sangyo and Shinshu Universities for their valuable discussions and comments. We gratefully acknowledge the financial support from the Japan Society for the Promotion of Science (JSPS), KAKENHI Grant Numbers JP15H03349 and JP15H05728, Grantin-Aid for JSPS Fellows Grant Number JP16J02442, and the program of the Joint Usage/Research Center for "Behavioral Economics" at ISER, Osaka University. The usual disclaimer is applicable.

${ }^{\dagger}$ Noriaki Matsushima, Institute of Social and Economic Research, Osaka University, Mihogaoka 6-1, Ibaraki, Osaka, 567-0047, Japan. Phone: (81)-6-6879-8571. Fax: (81)-6-6879-8583. E-mail: nmatsush@iser.osaka-u.ac.jp

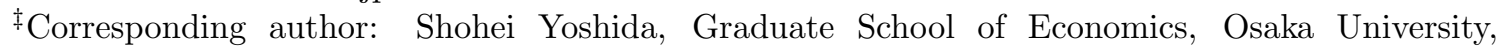
Machikaneyama 1-7, Toyonaka, Osaka 560-0043, Japan. Phone: (81)-6-6850-6111. Fax: (81)-6-68505205. E-mail: pge031ys@student.econ.osaka-u.ac.jp. 


\section{Introduction}

Considering the recent growth of dominant retailers such as Wal-Mart and Toys "R" Us, policy makers are now focusing on the influence of dominant retailers on market outcomes such as retail price, consumer surplus, and social welfare. Since Galbraith's (1952) argument on countervailing power, many researchers have investigated this topic in various models (e.g., von Ungern-Sternberg, 1996; Dobson and Waterson, 1997; Chen, 2003; Inderst and Valletti, 2011; Iozzi and Valletti, 2014; Gaudin, 2016a, 2016b; Chen et al., 2016). ${ }^{1}$

These previous papers, however, have not considered the dominant retailers as sales promoters. When consumers do not exactly judge the real quality of a product before and/or after the purchase, famous retailers' selling that product could enhance its credibility regarding quality. Several empirical studies show that the more favorable the store name perceptions, the higher are the buyers' product quality perceptions (e.g., Dodds et al., 1991). ${ }^{2}$ This reputation concern of dominant retailers could influence their negotiations with suppliers. If dominant retailers have a reputation of possessing highquality trading products, the breakdown of their negotiations with suppliers could have a negative impact on the reputation of the latter's products' quality. This is because such products are not handled by these dominant retailers. As a result, the market demand for suppliers' products becomes lesser than the demand when the dominant retailers handle these products. ${ }^{3}$ Therefore, this kind of reputation matter provides dominant retailers an additional bargaining power, irrespective of that in the context

\footnotetext{
${ }^{1}$ Detailed discussions on buyer power are available in Chen (2007), Inderst and Shaffer (2007), and Inderst and Mazzarotto (2008).

2 Marvel and McCafferty (1984), Chu and Chu (1994), and Clerides et al. (2008) also empirically investigate the effects of famous retailers on quality perception.

${ }^{3}$ Another interpretation of this scenario is as follows: since dominant retailers could undertake promotional activities, if they do not exist, some consumers would be unaware of the existence of the promoted product, which obviously reduces the market demand.
} 
of Nash bargaining.

To investigate the aspect mentioned above, a dominant retailer model in Chen (2003) is useful because his model distinguishes between two types of retailers - dominant and fringe. This model assumption allows us to investigate the role of dominant retailers in the context of the buyer-supplier relationship. Therefore, we incorporate a reputation matter into the model in Chen (2003), by also considering the recent result in Christou and Papadopoulos (2015), which is a modification of Chen (2003).

The market structure in our model is as follows. A monopoly supplier distributes its product through two channels. One channel is a dominant retailer that has a positive constant marginal cost. The dominant retailer and the supplier negotiate their trading terms (a two-part tariff contract) through Nash bargaining. The other channel comprises fringe retailers that have an increasing marginal cost technology, which is efficient for small quantities. Each fringe retailer is a price-taker at the retail level and sets its own quantity, which competes with the demand for the dominant retailer. Each of them is also a price-taker in the trade with the monopoly supplier, who unilaterally offers nondiscriminatory two-part tariff contracts to these fringe retailers. Under the framework, if the negotiation between the supplier and the dominant retailer breaks down, the retail price is determined to equalize the total quantities supplied by the fringe retailers and the market demand that has consequently reduced. The degree of market shrinkage depends on the importance of the dominant retailer as a sales promoter of the product.

There are several differences among Chen (2003), Christou and Papadopoulos (2015), and this study, regarding the retail market environments during negotiation breakdown between the dominant retailer and the supplier. In Chen (2003), the retail market is inactive; in Christou and Papadopoulos (2015), it is active and does not shrink; while in our study, it is active and does shrink. ${ }^{4}$ Chen (2003) shows that an increase in the

\footnotetext{
4 There is another difference between the three studies. Pertaining to negotiations between the
} 
buyer power possessed by a dominant retailer could decrease the retail prices for consumers. However, regarding correcting for payoffs and outside options in Chen (2003), Christou and Papadopoulos (2015) show that the countervailing power does not affect the equilibrium prices, that is, they show the "neutrality result." 5

Our paper shows that contrary to the neutrality result in Christou and Papadopoulos (2015), an increase in the buyer power possessed by a dominant retailer could decrease the retail prices for consumers, as in Chen (2003), even when the demand shrinkage through negotiation breakdown is minimal. Furthermore, if the bargaining power of the dominant retailer is strong, several unconventional negative results could arise: (i) Given that the number of fringe retailers is large, an increase in their number is more likely to increase the retail price; (ii) Efficiency improvements at the retail level increase the retail price. These unconventional negative impacts of efficiency improvements are new findings in the context of vertical relations. We can conclude that a strong bargaining power of the dominant retailer may cause unexpected negative impacts of efficiency improvements at the retail level on the retail price, although such a strong bargaining power by itself reduces the retail price.

The explanation behind the first result is as follows. A change in the bargaining power generates sales-shifting across retailers. For the supplier, a loss of bargaining power over the dominant retailer leads to a lower share of industry profits. This negative effect of the loss of bargaining power on the supplier is offset by a higher share of its outside options. In Christou and Papadopoulos (2015), a possible gain from its outside option completely negates the loss. In contrast, in our setting, if the dominant supplier and the dominant retailer, Christou and Papadopoulos (2015) and our study consider the supplier's profits from fringe retailers, unlike Chen (2003).

${ }^{5}$ Erutku (2005) also relaxes several assumptions in Chen (2003). Erutku (2005) changes the following: (i) the bargaining process between a dominant retailer (called "a national retailer" in his paper) and a monopoly manufacturer; and (ii) strategic interactions between the dominant retailer and its rival. He shows that the price of the dominant retailer monotonically decreases according to its bargaining power, although that of the rival has an inverted U-shaped relation to this parameter. 
retailer functions as a sales promoter, the supplier's gain from its outside option is not sufficient to negate the loss of bargaining power due to demand shrinkage through negotiation breakdown. This is why an increase in buyer power decreases retailer prices. We also explain the reason for the unconventional negative results. Since the mechanisms behind the results are partially shared, we only explain the reason behind the second unconventional negative result, that is, efficiency improvements in the retail level increase the retail price if the dominant retailer's bargaining power is strong. When the bargaining power of the dominant retailer is strong, the supplier's dependence on the fringe retailers is high because the profitability of trading with them is larger. This implies that the efficiency of the fringe retailers is not good due to their increasing marginal cost technology. An efficiency improvement of the dominant retailer improves the supplier's profitability of trade with the dominant retailer, leading to a shift of supply from the fringe retailers to the dominant retailer. The production shift is significant when their efficiency is not good, that is, when the dominant retailer's bargaining power is strong. Due to the significant production reduction by the fringe retailers, the dominant retailer obtains sufficient leeway to increase its retail price. Consequently, the retail price increases when the efficiency of the dominant retailer improves.

The rest of this paper proceeds as follows. Section 2 describes the model. Section 3 presents the equilibrium outcome and the results of comparative statics. Section 4 concludes the paper. The Appendix provides the proofs of the lemmas and propositions in Section 3.

\section{Model}

This section presents the basic model, which is an extension of Chen (2003), and Christou and Papadopoulos (2015). Consider a monopoly supplier that produces an intermediate good without any cost, and one dominant and $n$ fringe retailers that purchase 
the intermediate good from the supplier. Each retailer converts one unit of the intermediate good to one unit of final good without any cost. However, each retailer must incur an operational cost to handle the final good. The dominant retailer has a constant marginal cost $c$ to handle one unit of the final good. In contrast, each fringe retailer has an increasing marginal cost $M C\left(q_{f}\right)=d q_{f}$, where $d$ is a positive constant and $q_{f}$ is the quantity of the final good handled by the typical fringe retailer. These assumptions reflect that the fringe retailers are more efficient at small operational scales, while the dominant retailer is more efficient at a large scale. The demand function for the final good $D$ is given as $D(p)=a-b p$, where $a$ and $b$ are positive constants and $p$ is the retail price. ${ }^{6}$

The dominant retailer negotiates with the supplier over a two-part tariff contract, $w_{d} q_{d}+F_{d}$, where $w_{d}$ is the wholesale price, $q_{d}$ is the quantity purchased by the retailer, and $F_{d}$ is the fee. The fringe retailers are price-takers both in the input and final good markets.

In Stage 1, the monopoly supplier unilaterally offers a two-part tariff contract, $w_{f} q_{f}+F_{f}$, to each fringe retailer, where $w_{f}$ is the wholesale price, and $F_{f}$ is the fee. The supplier commits its offers.

In Stage 2, the supplier and the dominant retailer negotiate over the two-part tariff contract, $w_{d} q_{d}+F_{d}$. The bargaining power of the dominant retailer is $\gamma \in(0,1)$. If the negotiation breaks down, the market is still active but shrinks to $k D(p)(k \leq 1)$. This assumption reflects the role of the dominant retailer as a sales promoter. The case of $k=1$ is equivalent with that in Christou and Papadopoulos (2015).

In Stage 3, considering the production technology of the fringe retailers, the dominant retailer sets the retail price $p$. Given $p$, each fringe retailer determines its quantity. If the negotiation broke down in Stage 2, $p$ is determined to equalize the shrunken de-

\footnotetext{
${ }^{6}$ This functional form follows that in Christou and Papadopoulos (2015), although Chen (2003) mainly uses a general one.
} 
mand $k D(p)$ and the total quantities supplied by the fringe retailers. This condition is further explained in Section 3.

We assume the following to assure that equilibrium outcomes are positive values, and that second-order conditions are satisfied:

$$
c<\frac{a d k\left\{b^{2} d^{2} k+b d n[1-2 \gamma+2(1+\gamma) k]+2 n^{2}[1-(1-k) \gamma]\right\}}{(b d+n)(b d k+n)[b d k+2 n(1-(1-k) \gamma)]} \equiv \bar{c} .
$$

This condition is derived from the threshold value of $c$, which makes the outside payoff of each fringe retailer zero, and also determines the lowest value of $k$, which is strictly positive.

\section{Analysis}

We first derive the equilibrium outcome in the game, and then provide the results of the comparative statics.

\subsection{Equilibrium outcome}

Our main objective is to discuss how formulating disagreement payoffs influences the equilibrium property. Before this, we first solve the game by backward induction.

Stage 3 The mathematical procedure is completely the same as that in Christou and Papadopoulos (2015). In Stage 3, given the dominant retailer's retail price $p$ and the contract term $\left(w_{f}, F_{f}\right)$, each fringe retailer faces the following maximization problem:

$$
\max _{q_{f}} \pi_{f}=\left(p-w_{f}\right) q_{f}-\frac{d q_{f}^{2}}{2}-F_{f}
$$

This leads to the supply function of each fringe retailer, $s(\cdot)$,

$$
q_{f}^{*}\left(w_{f}\right)=s\left(p-w_{f}\right) \equiv\left(p-w_{f}\right) / d
$$

The residual demand for the dominant retailer is given as $D(p)-n s\left(p-w_{f}\right)$. Anticipating the decisions of the fringe retailers, the dominant retailer solves the following 
maximization problem:

$$
\max _{p} \pi_{d}=\left(p-c-w_{d}\right)\left[D(p)-n s\left(p-w_{f}\right)\right]-F_{d}
$$

This leads to the following retail price:

$$
p^{*}\left(w_{d}, w_{f}\right)=\frac{a d+n w_{f}+(b d+n)\left(c+w_{d}\right)}{2(b d+n)} .
$$

Stage 2 Anticipating the third-stage outcome, the supplier and the dominant retailer negotiate over the two-part tariff contract, $w_{d} q_{d}+F_{d}$. Let $\pi_{s}$ be the profit of the monopoly supplier. The bargaining problem is $D_{d}^{s}=\left\{\pi_{s}, \pi_{d}\right\}$, with the disagreement payoffs for the supplier and the dominant retailer being $\left(O_{s}, O_{d}\right)$, respectively, where:

$$
\begin{gathered}
\pi_{s}\left(w_{d}, w_{f}, F_{d}, F_{f}\right)=F_{d}+w_{d}\left[D\left(p^{*}\left(w_{d}, w_{f}\right)\right)-n s\left(p^{*}\left(w_{d}, w_{f}\right)-w_{f}\right)\right] \\
+n\left[F_{f}+w_{f} s\left(p^{*}\left(w_{d}, w_{f}\right)-w_{f}\right)\right] \\
\pi_{d}\left(w_{d}, w_{f}, F_{d}\right)=\left(p^{*}\left(w_{d}, w_{f}\right)-c-w_{d}\right)\left[D\left(p^{*}\left(w_{d}, w_{f}\right)\right)-n s\left(p^{*}\left(w_{d}, w_{f}\right)-w_{f}\right)\right] \\
O_{s}=n\left[F_{f}+w_{f} s\left(p_{o}-w_{f}\right)\right], \\
\quad \text { where } k D\left(p_{o}\right)=n s\left(p_{o}-w_{f}\right) \text { and } k \in[0,1]
\end{gathered}
$$

The equation, $k D\left(p_{o}\right)=n s\left(p_{o}-w_{f}\right)$ in $(4)$, is the demand-equal-supply condition, in which the negotiation between the supplier and the dominant retailer breaks down. The assumption of the supplier's disagreement payoff reflects the importance of the dominant retailer to promote the supplier's good. The lowest value of $k$ in (1) is sufficient to secure that the profit of each fringe firm is nonnegative when the negotiation between the supplier and the dominant retailer breaks down.

By solving the following maximization problem, we derive the outcome of bargaining:

$$
\max _{\left(w_{d}, F_{d}\right)}\left[\pi_{s}\left(w_{d}, w_{f}, F_{d}, F_{f}\right)-O_{s}\right]^{1-\gamma}\left[\pi_{d}\left(w_{d}, w_{f}, F_{d}\right)\right]^{\gamma}
$$


The maximization problem leads to:

$$
\begin{aligned}
w_{d}\left(w_{f}\right) & =\frac{n w_{f}}{b d+n} \\
F_{d}\left(w_{f}\right) & =\frac{(1-\gamma)(b d k+n)(a d-(b d+n) c)^{2}-4(1-k) \gamma d n^{2} w_{f}\left(a-b w_{f}\right)}{4 d(b d+n)(b d k+n)} .
\end{aligned}
$$

Stage 1 The profit of the monopoly supplier is:

$$
\begin{aligned}
\pi_{s}\left(w_{f}, F_{f}\right)=F_{d}\left(w_{f}\right)+w_{d}\left[D\left(p^{*}\left(w_{d}\left(w_{f}\right), w_{f}\right)\right)\right. & \left.-n s\left(p^{*}\left(w_{d}\left(w_{f}\right), w_{f}\right)-w_{f}\right)\right] \\
& +n\left[F_{f}+w_{f} s\left(p^{*}\left(w_{d}\left(w_{d}\right), w_{f}\right)-w_{f}\right)\right] .
\end{aligned}
$$

The monopoly supplier sets $w_{f}$ and $F_{f}$ to maximize its profit, leading to:

$$
\begin{aligned}
& w_{f}^{*}=\frac{[(b d k+n)(b d+2 n)-2 n(1-k)(b d+n) \gamma] a-b(b d k+n)(b d+n) c}{2 b(b d k+n)(b d+2 n)-4(1-k) b(b d+n) n \gamma}, \\
& F_{f}^{*}=\frac{(b d+n)^{2}(b d k+n-(1-k) n \gamma)^{2} c^{2}}{2 d[(b d k+n)(b d+2 n)-2(1-k) n(b d+n) \gamma]^{2}}, \\
& \pi_{s}^{*}=\frac{(1-\gamma)(a d-c(b d+n))}{4 b d(2 \gamma(k-1) n(b d+n)+(b d+2 n)(b d k+n))} \\
& \times\{2 \gamma(k-1) n(a-b c)(b d+n)+(b d k+n)(a(b d+2 n)-b c(b d+3 n))\} \\
& +n\left[\frac{(b d+n)^{2}(b d k+n-(1-k) n \gamma)^{2} c^{2}}{2 d[(b d k+n)(b d+2 n)-2(1-k) n(b d+n) \gamma]^{2}}\right. \\
& +\frac{[(b d k+n)(b d+2 n)-2 n(1-k)(b d+n) \gamma] a-b(b d k+n)(b d+n) c}{2 b(b d k+n)(b d+2 n)-4(1-k) b(b d+n) n \gamma} \\
& \left.\times\left(\frac{2 a \gamma d k}{b d k+n}-\frac{2 c(b d+n)(b(\gamma-2) d k+2(\gamma-1) n(\gamma(k-1)+1))}{2 \gamma(k-1) n(b d+n)+(b d+2 n)(b d k+n)}\right)\right], \\
& \pi_{d}^{*}=\left(p^{*}-c-w_{d}^{*}\right)\left[D\left(p^{*}\right)-n s\left(p^{*}-w_{f}^{*}\right)\right]-F_{d}^{*} \\
& =\frac{(a d-(n+b d) c)^{2}}{4 d(n+b d)}-\left\{\frac{(1-\gamma)(a d-(n+b d) c)^{2}}{4 d(n+b d)}\right. \\
& \left.-\frac{\gamma(1-k) n^{2}}{4 b(n+b d)(n+b d k)}\left(a^{2}-\frac{(b(n+b d)(n+b d k) c)^{2}}{((n+b d k)(2 n+b d)-2 \gamma(1-k) n(n+b d))^{2}}\right)\right\} \text {. }
\end{aligned}
$$


We obtain the values in equilibrium:

$$
\begin{aligned}
& p^{*}=\frac{[(b d k+n)(b d+2 n)-2(1-k)(b d+n) n \gamma] a+b(b d+n)(b d k+n-2(1-k) n \gamma) c}{2 b(b d k+n)(b d+2 n)-4(1-k) b(b d+n) n \gamma}, \\
& w_{d}^{*}=\frac{n}{b d+n} \frac{[(b d k+n)(b d+2 n)-2 n(1-k)(b d+n) \gamma] a-b(b d k+n)(b d+n) c}{2 b(b d k+n)(b d+2 n)-4(1-k) b(b d+n) n \gamma}, \\
& F_{d}^{*}=\left\{\frac{(1-\gamma)(a d-(n+b d) c)^{2}}{4 d(n+b d)}\right. \\
& \left.-\frac{\gamma(1-k) n^{2}}{4 b(n+b d)(n+b d k)}\left(a^{2}-\frac{(b(n+b d)(n+b d k) c)^{2}}{((n+b d k)(2 n+b d)-2 \gamma(1-k) n(n+b d))^{2}}\right)\right\}, \\
& q_{f}^{*}=\frac{c(b d+n)[b d k+n(1-(1-k) \gamma)]}{\left[b^{2} d^{2} k+2 n^{2}(1-(1-k) \gamma)+b d n(1-2 \gamma+2 k(1+\gamma))\right] d}, \\
& q_{d}^{*}=\frac{a d-(b d+n) c}{2 d} \text {. }
\end{aligned}
$$

\subsection{Comparative statics}

We provide several results of comparative statics.

First, we examine whether Christou and Papadopoulos's (2015) neutrality result holds in our setting.

Lemma 1 An increase in the countervailing power decreases the wholesale prices for the dominant and fringe retailers if $k<1$, that is, $\partial w_{d}^{*} / \partial \gamma<0$ and $\partial w_{f}^{*} / \partial \gamma<0$ if $k<1$.

In contrast to the results of Chen (2003) $\left(\partial w_{d} / \partial \gamma=0, \partial w_{f} / \partial \gamma<0\right)$, and those of Christou and Papadopoulos (2015) $\left(\partial w_{d} / \partial \gamma=0, \partial w_{f} / \partial \gamma=0\right)$, the countervailing power affects both wholesale prices when we consider demand shrinkage under negotiation breakdown. That is, we obtain different results in Lemma 1.

The partial derivative of $p^{*}$ with respect to $\gamma$ is:

$$
\frac{\partial p^{*}}{\partial \gamma}=-\frac{(1-k)(b d+n)(b d k+n) n^{2} c}{[(b d k+n)(b d+2 n)-2(1-k)(b d+n) n \gamma]^{2}}
$$

Thus, we obtain the following result: 
Proposition 1 An increase in the countervailing power decreases the retail price, and increases consumer surplus if $k<1$, that is, $\partial p^{*} / \partial \gamma<0$ if $k<1$.

To explain the mechanism behind Proposition 1, we first explain Christou and Papadopoulos's (2015) neutrality result. Their result comes from the non-profitability of "sales-shifting" across retailers. For the supplier, a loss of bargaining power leads to a lower share of the industry profits, which is nevertheless offset by a higher share of its outside option. If demand and marginal cost functions are linear, a possible gain from its outside option completely negates the loss. Thus, they have $\partial w_{f}^{*} / \partial \gamma=0$.

In contrast, our result shows that their assumption regarding the supplier's outside option $\left(O_{s}\right)$ is crucial to derive their neutrality result. In other words, if the dominant retailer works as a sales promoter of the supplier's product, the supplier's gain from its outside option is not sufficient to negate the loss of bargaining power. To overcome this loss, the supplier makes fringe retailers stronger by decreasing $w_{f}$. Although Lemma 1 and Proposition 1 have contrasting effects on the quantity of each fringe retailer, the effect in Lemma 1 dominates that in Proposition 1, leading to:

Lemma $2 \partial q_{f}^{*} / \partial \gamma>0$ for any $k<1$. In addition, $\partial q_{f}^{*} / \partial k<0$.

Since a smaller $k$ reflects a stronger bargaining power of the dominant retailer, the effect of $k$ on $w_{f}^{*}, p^{*}$, and $q_{f}^{*}$ has a completely reverse relation to that of $\gamma$ on $w_{f}^{*}, p^{*}$, and $q_{f}^{*}$.

Following Chen (2003), we also investigate how an increase in the countervailing power influences the profits of the supplier and the dominant retailers. For analytical complexity, we only present a numerical example, Figure 1 that the dominant retailer's profit may decrease with the countervailing power as in Chen (2003). Corollary 2 in Christou and Papadopoulos (2015) shows that an increase in countervailing power always benefits the dominant retailer, which contrasts with Chen's (2003) result. In their model, the monotonic relation between countervailing power and the dominant 


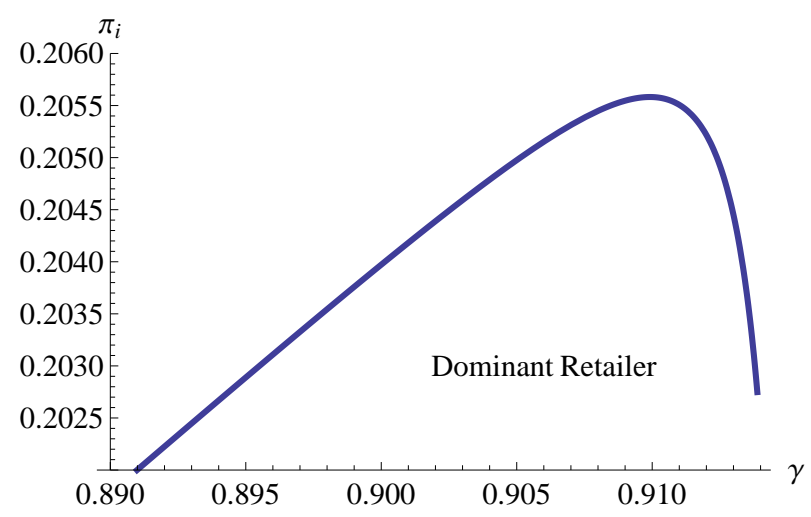

Figure 1: Relation between profits and $\gamma \cdot[a=1, b=1, c=0.001, d=5, n=5, k=0.1]$ retailer's profit comes from the fact that $\partial w_{f} / \partial \gamma=0$. Since the neutrality does not hold in our model, an increase in countervailing power has a different impact on the dominant retailer's profit, as shown in Figure 1.

Second, we show how the value of $k$ affects the profitabilities of the monopoly supplier and the dominant retailer. By using the first-order derivative of $\pi_{s}^{*}$ with respect to $k$, and the upper bound of $c$ in (1), we can show the following result:

Proposition 2 The profit of the monopoly supplier monotonically increases with an increase in $k$.

Since a larger $k$ reflects a stronger bargaining position of the monopoly supplier, in contrast to the effect of $\gamma$, the monopoly supplier benefits from an increase in $k$.

Proposition 3 The profit of the dominant retailer decreases with $k$ if $k$ is large enough.

This proposition is a flip side of Proposition 2 because a stronger bargaining position of the monopoly supplier is more likely to decrease the profit of the dominant retailer. ${ }^{7}$

Third, we examine how the number of fringe retailers, $n$, affects the retail price. Before we show the effect, we check the effect of $n$ on the wholesale prices:

7 Contrary to the relation between $\pi_{s}$ and $k$, there is no clear relation between $\pi_{d}$ and $k$ because $\partial \pi_{d}^{*} / \partial k$ can be positive for sufficiently small $k$. 
Lemma 3 An increase in the number of fringe retailers increases the wholesale prices for the dominant and fringe retailers if and only if

$$
n>b d\left(\frac{(1-k) \sqrt{2(1-k) k \gamma}-k(1-2(1-k) \gamma)}{1-2(1-k) k \gamma}\right) .
$$

The reason behind the result is as follows. An increase in $n$ has two major effects on the wholesale prices. First, the dominant retailer's residual demand shrinks, leading to a decrease in its retail price. This retail price reduction decreases both the wholesale price for the dominant retailer and the quantity of each fringe retailer. The latter quantity reduction also decreases the wholesale price for each fringe retailer. The larger the number of fringe retailers, the smaller is the marginal effect of residual demand shrinkage (we can check this by differentiating $p^{*}\left(w_{d}, w_{f}\right)$ with respect to $n$ twice). ${ }^{8}$ Second, total input demands from fringe retailers expand, leading to an increase in the wholesale price for them. This demand expansion provides the supplier a better outside option in negotiation with the dominant retailer, leading to an increase in its wholesale price. The larger the number of fringe retailers, the larger is the supplier's profit from supplying to fringe retailers, enhancing the former's outside option.

When $n$ is large, the second effect dominates the first one, that is, the wholesale prices for these retailers increase with $n$ when $n$ is large.

Lemma 3 leads to the following result:

Proposition 4 An increase in the number of fringe retailers, $n$, increases the retail price and decreases consumer surplus if and only if:

$$
n>\frac{b d k(\sqrt{2 \gamma}(1-k)+1)}{2(1-k)^{2} \gamma-1} \text { and } k<1-\frac{1}{\sqrt{2 \gamma}} .
$$

As in Lemma 3, the supplier may induce the dominant retailer to reduce its output, inducing fringe retailers to produce more. When the former reduction dominates the

\footnotetext{
8 Simple calculations lead to $\partial p^{*}\left(w_{d}, w_{f}\right) / \partial n=-d\left(a-b w_{f}\right) / 2(b d+n)^{2}(<0)$ and $\partial^{2} p^{*}\left(w_{d}, w_{f}\right) / \partial n^{2}=d\left(a-b w_{f}\right) /(b d+n)^{3}(>0)$ (note that $D(p)=a-b p$ and $w_{f}$ must be smaller than the retail price $p$, which is smaller than $a / b)$.
} 
latter expansion, the total output decreases, leading to an increase in retail price. Note that the right-hand side of the first fraction decreases with an increase in $\gamma$. That is, an increase in the number of fringe retailers is less likely to improve the consumer surplus when the dominant retailer has a strong bargaining power.

Fourth, we check how the efficiency of the dominant retailer, $c$, influences the retail price and the consumer surplus. A simple calculation leads to the following result:

Proposition 5 A decrease in the marginal cost of the dominant retailer, $c$, increases the retail price and decreases the consumer surplus if and only if:

$$
\gamma>\frac{b d k+n}{2 n(1-k)} \text { and } k<\frac{n}{b d+2 n}
$$

The explanation behind the result is as follows. As mentioned in Lemma 2, an increase in $\gamma$ increases the quantity of each fringe retailer, which implies that the supplier's dependence on the fringe retailers increases. This also implies that the efficiency of the fringe retailers reduces due to their increasing marginal cost technology. A decrease in $c$ improves the profitability of trade with the dominant retailer, subsequently shifting the supply from the fringe retailers to the dominant retailer. This shift is more significant when the efficiency of the fringe retailers is worse, that is, when $\gamma$ is larger. Due to the significant production reduction by the fringe retailers, the dominant retailer obtains adequate leeway to increase its retail price. Note that, as pointed out in Lemma 2, a decrease in $k$ is similar to an increase in $\gamma$. In fact, the condition in Proposition 5 gets looser as $k$ decreases. Figure 2 presents a numerical example of Proposition 5.

We briefly discuss the implication of this result on empirical research. When researchers empirically estimate firms' cost structures, positive correlations between the observed retail prices and marginal costs are presumed. Although such presumptions are almost always reasonable, Proposition 5 shows that they might not be reasonable 


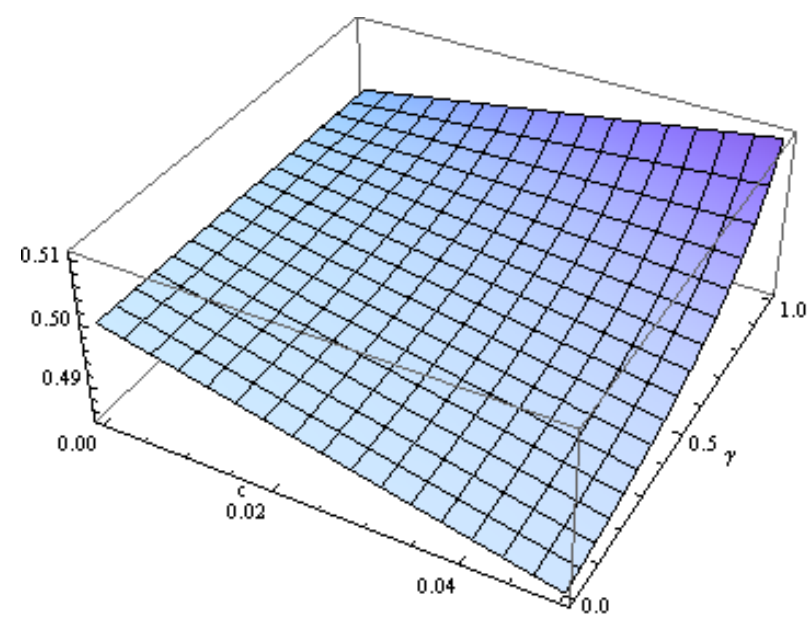

Figure 2: The relation between consumer surplus and $\gamma$ and $c .[a=1, b=1, d=3, n=$ $5, k=0.3]$

if we empirically estimate firms' cost structures in oligopoly markets with a monopoly supplier, and one dominant and several fringe retailers.

Finally, we check how the efficiency of fringe retailers, $d$, influences the retail price and consumer surplus. A simple calculation leads to the following result. ${ }^{9}$

Proposition 6 A decrease in the cost parameter of each fringe retailer, $d$, increases the retail price and decreases the consumer surplus if and only if

$$
\gamma>\frac{(b d k+n)^{2}}{2 n^{2}(1-k)^{2}} \quad \text { and } \quad k<\frac{n((2-\sqrt{2}) n-(\sqrt{2}-1) b d)}{2 n^{2}-b^{2} d^{2}} .
$$

Proposition 6 is parallel to Proposition 5. When $\gamma$ is large, the supplier induces the fringe retailers to produce more. In addition, the improvement of the fringe retailers' efficiency is more beneficial when $\gamma$ is large (i.e., the fringe retailers produce excessively). This renders the supplier to have a strong incentive for output-shifting from the dominant retailer to the fringe retailers (in fact, we have $\partial^{2} w_{f}^{*}\left(w_{d}^{*}\right) / \partial d \partial \gamma<0$ ). Although the total output of fringe retailers increases with their efficiency improvement,

\footnotetext{
9 The sign of $2 n^{2}-b^{2} d^{2}$ in the last fraction is irrelevant.
} 
the dominant retailer's output shrinks significantly, and then the total quantity may decrease.

\section{Conclusion}

We consider a downstream oligopoly model with one monopoly supplier, one dominant retailer, and fringe retailers, by taking into account the role of the dominant retailer as a sales promoter of the supplier's product. We assume that the existence of the dominant retailer is important to sustain the downstream demand size at a certain level. More concretely, the demand size shrinks if the negotiation between the dominant retailer and the supplier breaks down.

We show that an increase in the buyer power possessed by a dominant retailer could decrease the retail prices for consumers as in Chen (2003), even when the demand shrinkage through negotiation breakdown is minimal. Furthermore, if the bargaining power of the dominant retailer is strong, several unconventional negative results could

arise: (i) An increase in the number of fringe retailers is more likely to increase the retail price if their number is large; (ii) Efficiency improvements at the retail level increase the retail price. These unconventional negative impacts of efficiency improvements are new insights derived in our paper. We can conclude that, in a retail market with a dominant retailer that trades with a strong supplier, a strong bargaining power of the dominant retailer may cause unexpected negative impacts of efficiency improvements in the retail level on the retail price, although such a strong bargaining power in itself reduces the retail price.

We could extend the model to a two-region model in which products in two regions are geographically differentiated, and the retail market in each region comprises a dominant and several fringe retailers that trade with a local monopoly supplier. That is, each region is connected through the retail level transactions, which restrict the monopoly 
power of the dominant retailer in each region. Although the extension complicates the analysis, this could be a potential avenue for future research.

\section{Appendix: Proofs}

\section{Proof of Lemma 1.}

Differentiating $w_{f}^{*}$ with respect to $\gamma$, we have:

$$
\frac{\partial w_{f}^{*}}{\partial \gamma}=-\frac{(1-k)(b d k+n)(b d+n)^{2} c n}{\left[b^{2} d^{2} k+2 n^{2}[1-(1-k) \gamma]+b d n(1-2 \gamma+2 k(1+\gamma))\right]^{2}}<0 .
$$

Note that $w_{d}^{*}=n w_{f}^{*} /(b d+n)$ also decreases with $\gamma$.

\section{Proof of Proposition 1.}

We have already shown that $\partial p^{*} / \partial \gamma<0$ if $k<1$. We define consumer surplus in equilibrium as follows:

$$
C S=\frac{b\left(q_{d}^{*}+n q_{f}^{*}\right)^{2}}{2}
$$

Differentiating $C S$ with respect to $\gamma$, we have

$$
\frac{\partial C S}{\partial \gamma}=b\left(q_{d}^{*}+n q_{f}^{*}\right) \frac{\partial\left(q_{d}^{*}+n q_{f}^{*}\right)}{\partial \gamma}=-b^{2}\left(q_{d}^{*}+n q_{f}^{*}\right) \frac{\partial p^{*}}{\partial \gamma}>0
$$

if $k<1$.

\section{Proof of Lemma 2.}

Differentiating $q_{f}^{*}$ with respect to $\gamma$, we have:

$$
\frac{\partial q_{f}^{*}}{\partial \gamma}=\frac{b c n(1-k)(b d+n)(b d k+n)}{\left[b^{2} d^{2} k+2 n^{2}[1-(1-k) \gamma]+b d n(1-2 \gamma+2 k(1+\gamma))\right]^{2}}>0,
$$

if $k<1$. Similarly, differentiating $q_{f}^{*}$ with respect to $k$, we have:

$$
\frac{\partial q_{f}^{*}}{\partial k}=-\frac{b c n \gamma(b d+n)^{2}}{\left[b^{2} d^{2} k+2 n^{2}[1-(1-k) \gamma]+b d n(1-2 \gamma+2 k(1+\gamma))\right]^{2}}<0 .
$$




\section{Proof of Proposition 2.}

Differentiating $\pi_{s}^{*}$ with respect to $k$, we have:

$$
\begin{aligned}
\frac{\partial \pi_{s}^{*}}{\partial k}= & \frac{n^{2} \gamma\left\{b^{2} d^{2} k+2 n^{2}[1-(1-k) \gamma]+b d n(1-2 \gamma+2 k(1+\gamma))\right\}^{2} a^{2}}{4 b(b d k+n)^{2}\left[b^{2} d^{2} k+2 n^{2}[1-(1-k) \gamma]+b d n(1-2 \gamma+2 k(1+\gamma))\right]^{2}} \\
& -\frac{n^{2} \gamma b^{2}(b d+n)^{2}(b d k+n)^{2} c^{2}}{4 b(b d k+n)^{2}\left[b^{2} d^{2} k+2 n^{2}[1-(1-k) \gamma]+b d n(1-2 \gamma+2 k(1+\gamma))\right]^{2}} .
\end{aligned}
$$

We thus obtain the following:

$$
\frac{\partial \pi_{s}^{*}}{\partial k}=0 \Leftrightarrow c=\frac{a\left(b^{2} d^{2} k+b d n(1-2 \gamma+2(1+\gamma) k)+2 n^{2}(1-\gamma(1-k))\right)}{b(b d+n)(b d k+n)} \equiv \hat{c} .
$$

Note that $\partial \pi_{s}^{*} / \partial k$ is decreasing with $c$. Since we can show that $\hat{c}>\bar{c}, \partial \pi_{s}^{*} / \partial k>0$ for all $c \in(0, \bar{c})$.

\section{Proof of Proposition 3.}

The partial differential of $\pi_{d}$ with respect to $k$ is:

$$
\frac{\partial \pi_{d}^{*}}{\partial k}=-\frac{\gamma n^{2} a^{2}}{4 b(n+b d k)^{2}}+\frac{\gamma n^{2} b(n+b d)^{2}((n+b d k)(2 n+b d)+2 \gamma(1-k) n(n+b d)) c^{2}}{4((n+b d k)(2 n+b d)-2 \gamma(1-k) n(n+b d))^{3}} .
$$

Since $\partial \pi_{d}^{*} /\left.\partial k\right|_{k=1}=-\gamma n^{2}\left((2 n+b d)^{2} a^{2}-b^{2}(n+b d)^{2} c^{2}\right) /\left(4 b(n+b d)^{2}(2 n+b d)^{2}\right)<0$ for any $c \in[0, \bar{c})$, the partial differential is negative around $k=1$.

\section{Proof of Lemma 3.}

Differentiating $w_{f}^{*}$ with respect to $n$, we have:

$$
\frac{\partial w_{f}^{*}}{\partial n}>0 \Leftrightarrow n>b d\left(\frac{(1-k) \sqrt{2(1-k) k \gamma}-k(1-2(1-k) \gamma)}{1-2(1-k) k \gamma}\right) .
$$

Note that $w_{d}^{*}=n w_{f}^{*} /(b d+n)$ also decreases with $n$.

\section{Proof of Proposition 4.}

Differentiating $p^{*}$ with respect to $n$, we have:

$$
\frac{\partial p^{*}}{\partial n}>0 \Leftrightarrow n>\frac{b d k(\sqrt{2 \gamma}(1-k)+1)}{2(1-k)^{2} \gamma-1} .
$$


The condition that the denominator is positive is $k<1-1 / \sqrt{2 \gamma}$.

Differentiating $C S$ with respect to $n$, we have:

$$
\frac{\partial C S}{\partial n}=b\left(q_{d}^{*}+n q_{f}^{*}\right) \frac{\partial\left(q_{d}^{*}+n q_{f}^{*}\right)}{\partial \gamma}=-b^{2}\left(q_{d}^{*}+n q_{f}^{*}\right) \frac{\partial p^{*}}{\partial n} .
$$

Therefore, the sign of that derivative is converse to that of price.

\section{Proof of Proposition 5.}

Differentiating $p^{*}$ with respect to $c$, we have:

$$
\begin{aligned}
\frac{\partial p^{*}}{\partial c} & =\frac{(b d+n)(b d k+n-2 \gamma n(1-k))}{2[(b d+2 n)(b d k+n)-2 \gamma n(1-k)(b d+n)]}<0 \\
& \Leftrightarrow \gamma>\frac{b d k+n}{2 n(1-k)} .
\end{aligned}
$$

The condition that the threshold value is less than one is: $k<n /(b d+2 n)$.

\section{Proof of Proposition 6.}

Differentiating $p^{*}$ with respect to $d$, we have:

$$
\begin{aligned}
\frac{\partial p^{*}}{\partial d} & =\frac{b c n\left[(b d k+n)^{2}-2 \gamma n^{2}(1-k)^{2}\right]}{2[(b d+2 n)(b d k+n)-2 \gamma n(1-k)(b d+n)]^{2}}<0 \\
& \Leftrightarrow \gamma>\frac{(b d k+n)^{2}}{2 n^{2}(1-k)^{2}} .
\end{aligned}
$$

The condition that the threshold value is less than one is $k<n((2-\sqrt{2}) n-(\sqrt{2}-$ 1)bd)/(2n $\left.-b^{2} d^{2}\right)$.

\section{References}

[1] Chen, Z., 2003. Dominant retailers and the countervailing-power hypothesis. RAND Journal of Economics 34, 612-625.

[2] Chen, Z., 2007. Buyer power: Economic theory and antitrust policy. Zerbe, R.O. and J.B. Kirkwood (eds.) Research in Law and Economics (Research in Law and Economics, Volume 22), 17-40, Emerald Group Publishing Limited, Bingley UK. 
[3] Chen, Z., Ding, H., Liu, Z., 2016. Downstream competition and the effects of buyer power. Review of Industrial Organization 49, 1-23.

[4] Christou, C., Papadopoulos, K. G., 2015. The countervailing power hypothesis in the dominant firm-competitive fringe model. Economics Letters 126, 110-113.

[5] Chu, W., Chu, W., 1994. Signaling quality by selling through a reputable retailer: An example of renting the reputation of another agent. Marketing Science 13, $177-189$.

[6] Clerides, S., Nearchou, P., Pashardes, P., 2008. Intermediaries as quality assessors: Tour operators in the travel industry. International Journal of Industrial Organization 26, 372-392.

[7] Dobson, P. W., Waterson, M., 1997. Countervailing power and consumer prices. Economic Journal 107, 418-430.

[8] Dodds, W. B., Monroe, K. B., Grewal, D., 1991. Effects of price, brand, and store information on buyers' product evaluations. Journal of Marketing Research 28, 307-319.

[9] Erutku, C., 2005. Buying power and strategic interactions. Canadian Journal of Economics 38, 1160-1172.

[10] Galbraith, J. K., 1952. American capitalism: The concept of countervailing power. Houghton Mifflin, Boston, MA.

[11] Gaudin, G., 2016a. Vertical bargaining and retail competition: What drives countervailing power? (Last Access: October 4, 2016).

Available at SSRN: http://ssrn.com/abstract $=2655726$ 
[12] Gaudin, G., 2016b. Pass-through, vertical contracts, and bargains. Economics Letters $139,1-4$.

[13] Inderst, R., Mazzarotto, N., 2008. Buyer power in distribution. In: Collins, W.D. (Ed.). Issues in Competition Law and Policy Volume 3 (ABA Section of Antitrust Law), 1611-1637, ABA Book Publishing, Chicago USA.

[14] Inderst, R., Shaffer, G., 2007. Retail mergers, buyer power, and product variety. Economic Journal 117, 45-67.

[15] Inderst, R., Valletti, T., 2011. Buyer power and the "waterbed effect." Journal of Industrial Economics 59, 1-20.

[16] Iozzi, A., Valletti, T., 2014. Vertical bargaining and countervailing power. American Economic Journal: Microeconomics 6, 106-135.

[17] Marvel, H. P., McCafferty, S., 1984. Resale price maintenance and quality certification. RAND Journal of Economics 15, 346-359.

[18] von Ungern-Sternberg, T., 1996. Countervailing power revisited. International Journal of Industrial Organization 14, 507-519. 